\title{
Stability of Biosynthesised Silver Nanoparticles Using Achyranthes aspera Roots and Its Characterization
}

\author{
P.M. Smitha ${ }^{1 *}$, Sharanagouda Hiregoudar ${ }^{1}$, Udaykumar Nidoni $^{1}$, \\ K.T. Ramappa ${ }^{1}$ and Sushilendra ${ }^{2}$ \\ ${ }^{1}$ Department of Processing and Food Engineering, College of Agricultural Engineering, \\ University of Agricultural Sciences, Raichur- 584 101, Karnataka, India \\ ${ }^{2}$ Department of Farm Machinery and Power Engineering, College of Agricultural \\ Engineering, University of Agricultural Sciences, Raichur- 584 101, Karnataka, India
}

*Corresponding author

\begin{tabular}{|c|c|}
\hline & A B S T R A C T \\
\hline & \multirow{6}{*}{$\begin{array}{l}\text { The present investigation was aimed to study the biosynthesis, stability and } \\
\text { characterization of silver nanoparticles using Achyranthes aspera root extract. Synthesis of } \\
\text { silver nanoparticles has been done by maintaining different } \mathrm{AgNO}_{3} \text { concentrations }(0.50 \text {, } \\
1.00,1.50 \text { and } 1.84 \mathrm{mM}) \text {, temperature }\left(25,45,75,105 \text { and } 125{ }^{\circ} \mathrm{C}\right) \text { and } \mathrm{pH} \text { conditions }(4 \text {, } \\
5,7,9 \text { and } 10 \text { ). By analysing the data obtained during stability study, it was found that, } \\
\text { combination of } \mathrm{AgNO}_{3} \text { of } 1.15 \mathrm{mM} \text { concentration, temperature at } 45^{\circ} \mathrm{C} \text { and pH of } 9 \text { was } \\
\text { the best condition to synthesize the stable } \mathrm{Ag} \mathrm{NPs} \text { for one month. Characterization of } \\
\text { synthesized silver nanoparticles was done by zetasizer, UV-Vis spectroscopy, scanning } \\
\text { electron microscopy (SEM), X-ray diffraction (XRD) and atomic force microscopy } \\
\text { (AFM). Particle size distribution of zetasizer indicated that the size of the biosynthesized } \\
\text { silver nanoparticles was } 23.21 \mathrm{~nm} \text { and UV-Vis spectroscopy showed its absorbance peak } \\
\text { at } 420 \mathrm{~nm} \text {, which confirmed the presence of Ag NPs. XRD analysis confirmed that, } \\
\text { resultant Ag NPs were face-centered cubic in nature and AFM analysis showed surface } \\
\text { area }\left(103.97 \mu \mathrm{m}^{2}\right) \text {, selected particle height }(0.12 \mu \mathrm{m}) \text { and width }(1.10 \mu \mathrm{m}) \text {. It was } \\
\text { concluded that, green synthesis was an eco-friendly and most economical way to produce } \\
\text { silver nanoparticles over the chemical and physical methods }\end{array}$} \\
\hline Keywords & \\
\hline $\begin{array}{l}\text { Biosynthesised Silver } \\
\text { Nanoparticles, } \\
\text { Achyranthes aspera, } \\
\text { Roots }\end{array}$ & \\
\hline Article Info & \\
\hline $\begin{array}{l}\text { Accepted: } \\
\text { 10 August } 2018 \\
\text { Available Online: } \\
\text { 10 September } 2018\end{array}$ & \\
\hline & \\
\hline
\end{tabular}

\section{Introduction}

Nanotechnology is considered as an emerging technology due to the possibility of advanced well-established products and to create new products with totally new characteristics and functions in a wide range of applications. It represents the design, production and application of materials at atomic, molecular and macromolecular scales in order to produce new nano-sized materials (Hahens et al., 2007) and it is mainly concerned with synthesis of nanoparticles of variable size, shape, chemical compositions and controlled dispersity with their potential use for human benefits (Elumalai et al., 2010).

An array of physical, chemical and microbial methods has been used for synthesis of metal nanoparticles of particular shape and size 
(Balagurunathan et al., 2011). Many of these methods involve the use of tedious hazardous chemicals or high energy requirements, which are rather difficult and tedious in purification (Ahmed et al., 2014).

Green synthesis provides advancement over chemical and physical methods as it is cost effective, environment friendly, easily scaledup and further there is no need to use toxic chemicals, high pressure and energy. The biological processes eliminate the elaborate process of maintaining cell cultures and can also be easily scaled-up for large-scale production of nanoparticles (Veeraswamy et al., 2011). During synthesis of nanoparticles, the parameters such as $\mathrm{pH}$, temperature, salt concentration and reducing agent have a significant influence on diameter, size distribution, shape, aggregation, state and stability. Thus, the optical properties of nanoparticles, conductivity and other characteristics may be changed (Kupiec et al., 2011).

Achyranthes aspera is a species of plant in the Amaranthaceae family. It is known as Uttarani in kannada language. It is an erect, annual or perennial herb of about 1-2 metre in height and is found as a weed on road sides, field boundaries and waste places throughout India and in South Andaman Islands (Amaladhas et al., 2013). Phytochemical investigations were revealed that, the presence of bioactive compounds like sterols, alkaloids, saponins, sapogenins, cardiac and glycosides in leaves and roots are responsible for the reduction of silver ions to silver nanoparticles (Ag NPs) (Triguna et al., 1992).

It is well known that, silver is an effective antimicrobial agent and possesses a strong antimicrobial activity against bacteria, viruses and fungi. The antimicrobial activity of silver nanoparticles is a result of well-developed surface (Kaviya et al., 2011). Because of their wide spread applications, the scientific community and industry have paid special attention to the synthesis of silver nanoparticles (Tran et al., 2013).

Various instrumental techniques were adopted to characterize the synthesized Ag NPs. The particle size measurement can be obtained by zetasizer, optical properties of the silver nanoparticles can be determined through UVVisible spectrophotometer, surface morphology by using scanning electron microscope (SEM), crystallinity can be measured by X-ray diffraction (XRD), surface and strength of nanoparticles can be measured by atomic force microscope (AFM) (Joseph et al., 2016).

\section{Materials and Methods}

\section{Biosynthesis of silver nanoparticles using Achyranthes aspera roots}

The biosynthesis of silver nanoparticles using A. aspera roots was carried out as described below.

\section{Preparation of Achyranthes aspera root extract}

A. aspera roots were thoroughly washed using distilled water to remove dirt and soil. Washed roots were cut into small pieces of length 10 $\mathrm{mm}$ and dried in a tray dryer (Macro scientific works, Mac 216, Delhi, India) at $50 \pm 2{ }^{\circ} \mathrm{C}$ for about 5 days. The dried roots were ground using pulveriser (M/S Sriram Machinery Works, model SRM-108, Tamil Nadu, India) to make them into a fine powder and passed through a 100 mesh sieve $(150 \mu \mathrm{m})$. Five grams of dried powder was added to $100 \mathrm{ml}$ of distilled water and the mixture was heated at $60{ }^{\circ} \mathrm{C}$ for about $30 \mathrm{~min}$ using water bath. Then, it was filtered through filter paper (Whatman No. 1). The filtrate was stored at 4 ${ }^{\circ} \mathrm{C}$ for further experiments. 


\section{Biosynthesis of silver nanoparticles using Achyranthes aspera root extract}

The root extract of $A$. aspera $(10 \mathrm{ml})$ was diluted with distilled water $(90 \mathrm{ml})$. Further, $1.5 \mathrm{mM} \mathrm{AgNO}_{3}$ solution was prepared and stored in brown bottle. $100 \mathrm{ml}$ of diluted root extract and $100 \mathrm{ml}$ of $\mathrm{AgNO}_{3}$ solution were taken in two separate beakers and heated at 60 ${ }^{\circ} \mathrm{C}$ for $30 \mathrm{~min}$ in water bath, cooled and kept for further use.

For synthesis of silver nanoparticles, $85 \mathrm{ml}$ of prepared $\mathrm{AgNO}_{3}$ solution was added to $15 \mathrm{ml}$ of prepared root extract and stirred with glass rod for $10 \mathrm{~min}$. The mixture was heated (45 min) using magnetic stirrer (M/s Tarsons, 6090, Kolkata, India) until colour changed.

Upon heating the chemical reaction took place resulting in colour change in the reactants from pale yellow to dark brown and the mixture was cooled. The appearance of brown colour indicated the formation of silver nanoparticles (Kalidasan and Yogamoorthi, 2014).

Central composite rotatable design (CCRD) and response surface methodology (RSM) can be an effective option for the optimization of variables for the synthesis of silver nanoparticles (Mitra and Meda, 2009). To study the optimum condition for the synthesis of silver nanoparticles, experiment was conducted at different conditions of $\mathrm{AgNO}_{3}$ concentrations $(0.50,1.00,1.50,1.83)$, temperature conditions $(25,45,75,105$ and $\left.125^{\circ} \mathrm{C}\right)$ and $\mathrm{pH}(4,5,7,9$ and 10$)$.

Centrifugation of biosynthesized Ag NPs was done at $10000 \mathrm{rpm}$ for $30 \mathrm{~min}$ using ultracentrifuge (Beckman Coulter, Optima maxTL, California, USA). The supernatant was collected and stored for further characterization (Kalidasan and Yogamoorthi, 2014).

\section{Characterization of biosynthesized Ag NPs}

\section{Particle size analysis}

Zetasizer (ZETA Sizer, nano383, Malvern, England) was used to measure average particle size $(\mathrm{nm})$ of $\mathrm{Ag}$ NPs. For the particle size analysis, supernatant of centrifuged silver nanoparticles was filled in cuvette up to $3 / 4^{\text {th }}$ of volume and placed in the dynamic light scattering chamber (Das et al., 2014).

\section{Absorbance peak analysis}

UV-Visible spectrophotometer refers to absorption spectrophotometer in the ultraviolet and visible spectral region of the electromagnetic spectrum, where molecules undergo electronic transition. Silver nanoparticles were characterized by using UV-Visible spectrophotometer (Schimadzu, UV-1800, Kyoto, Japan). The sample was prepared by diluting $1 \mathrm{ml}$ of Ag NPs into $2 \mathrm{ml}$ distilled water and measured the UV-Visible spectrum of Ag NPs solution (Habibi et al., 2017).

\section{Surface morphology analysis}

The morphological features of biosynthesized silver nanoparticles were studied by using scanning electron microscope (SEM) (Carl Zeiss Microscopy, EVO 10, Cambridge, UK). The SEM image of the Ag NPs surface was obtained by scanning it with a high energy beam of electrons in vacuum chamber. When the beam of electrons strikes the surface of the specimen and interacts with atoms of sample, it produces signals in the form of secondary electrons and back scattered electrons. These signals contain information about sample's surface morphology. Magnification can be adjusted from about 1 to 30,000 times to get clear morphology of silver nanoparticles at the accelerating voltage of 5 to $30 \mathrm{kV}$ with working distance at $10 \mathrm{~mm}$ (Haq et al., 2014). 


\section{Phase identification analysis}

$\mathrm{X}$-ray diffraction (XRD analysis) is a unique method for determination of crystallinity of a compound. Crystalline nature of the silver nanoparticles was measured on X-ray diffraction instrument (M/s Rigaku, Ultima 4, Tokyo, Japan) operated at $30 \mathrm{kV}$ and $100 \mathrm{~mA}$ (Plate 6). Spectrum was recorded by $\mathrm{CuK \alpha}$ radiation with wavelength of $1.5406 \AA$ in the $2 \theta$ range of $20-80^{\circ}$. Silver nanoparticles $(\sim 1 \mathrm{~g})$ were uniformly spread on glass sample holder and placed in scanner chamber. The set scan speed and step size of $0.30 \% \mathrm{~min}$ and $0.001 \mathrm{~s}$, respectively were fixed. The XRD pattern was recorded for phase identification of silver nanoparticles (Djangang et al., 2015).

\section{Analysis of surface topology}

Atomic force microscope (AFM) provides a 3D profile of the surface on a nanoparticle by measuring forces between a sharp probe $(<10$ $\mathrm{nm})$ and surface at very short distance $(0.20$ $10 \mathrm{~nm}$ probe sample separation). Samples for AFM were prepared by spin-coating the $\mathrm{Ag}$ NPs solution into the glass slide. The slide was dried at room temperature and subjected to AFM analysis (Trial SPM, Version 6.4.3, Trieste, Italy) (Hong et al., 2017).

\section{Results and Discussion}

Stability of biosynthesised silver nanoparticles using $A$. aspera root extract

During synthesis, addition of root extract of $A$. aspera into the beakers containing aqueous solution of silver nitrate led to the change in the colour of the solution from pale yellow to dark brown within reaction duration. This might be due to the reduction of $\mathrm{Ag}^{+}$ions, indicating the formation of Ag NPs.

Biosynthesized silver nanoparticles were checked for their stability by using zetasizer and UV-Visible spectrophotometer for 30 days at an interval of $12 \mathrm{~h}$. Data obtained from the stability study was analysed using central composite rotatable design (CCRD) and as well as Response surface methodology. From the analysed data, it was observed that 1.50 $\mathrm{mM} \mathrm{AgNO} 3$ concentration, $45^{\circ} \mathrm{C}$ temperature and $9 \mathrm{pH}$ was the best treatment combination (desirability $96.39 \%$ ) in terms of stability. During stability study, particle size of the Ag NPs sample prepared with above mentioned best combination was in the range of 19 to 81 $\mathrm{nm}$ and absorbance peak was varied from 404 to 434. These results are in good agreement with the results of Vanaja et al., (2013) who reported that, the $\mathrm{pH}$ of 8.20 and $\mathrm{AgNO}_{3}$ concentration of $1 \mathrm{mM}$ were favourable in biosynthesis of $\mathrm{Ag}$ NPs using Coleus aromaticus leaf extract.

\section{Characterization of biosynthesized silver nanoparticles}

\section{Particle size analysis}

The characterization of biosynthesized silver nanoparticles was done in terms of average particle diameter from the intensity distribution analysis by using zetasizer. The size distribution histogram of zetasizer indicated that, the size of the silver nanoparticles was $23.21 \mathrm{~nm}$ (Fig. 1). The variation in particle size was probably due to change in climatic conditions during biosynthesis (Zainala et al., 2013). The size and shape of metal nanoparticles are influenced by a number of factors including $\mathrm{pH}$, precursor concentration, time of incubation and temperature (Umoren et al., 2014).

Kalidasan and Yogamoorthi (2014) reported that, the size of biosynthesized Ag NPs using A. aspera root extract was $105 \mathrm{~nm}$. Beg et al., (2016) and Bobbu et al., (2016) reported that, an average particle size of biosynthesized 
silver nanoparticles were 19.60 and $25.50 \mathrm{~nm}$ using Pongamea pinnata seed and Achyranthes aspera leaf extract, respectively.

\section{Absorbance analysis}

The UV-Visible absorption spectra of biosynthesized silver nanoparticles exhibited characteristic surface plasmon resonance (SPR) band centered at wavelength of 420.80 $\mathrm{nm}$ and absorbance of 1.17 (Fig. 2). This observed intense band was attributed due to the excitation of free electrons in the nanoparticles which indicated the presence of silver nanoparticles.
Similar results were reported by Hafez et al., (2017), Halawani (2017) and Sivakumari et al., (2018) reported SPR band for biosynthesized silver nanoparticles using Morus nigra leaf extract (425 nm), Zizyphus spinachristi L. leaf extract $(414 \mathrm{~nm})$ and Achyranthes Aspera $(450 \mathrm{~nm})$.

\section{Surface morphology analysis}

The clear magnified (8.07 KX) SEM image at the accelerating voltage of $10.00 \mathrm{kV}$ with working distance of $9.50 \mathrm{~mm}$, showed that, uniformly distributed silver nanoparticles were spherical in shape (Fig. 3).

Fig.1 Particle size analysis of biosynthesized Ag NPs using zetasizer

\section{Results}
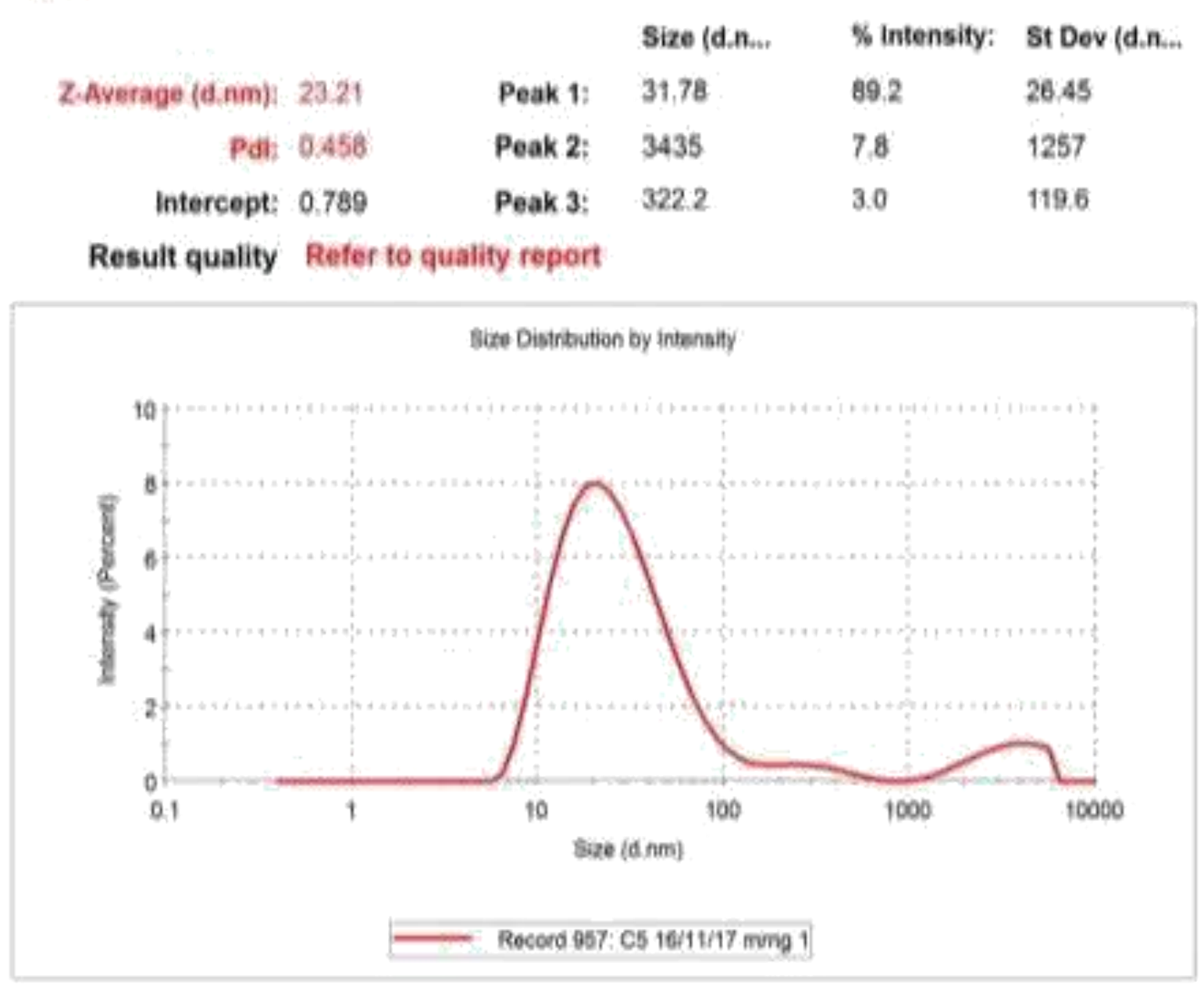
Fig.2 Absorbance analysis of biosynthesized Ag NPs using UV-Visible spectrophotometer

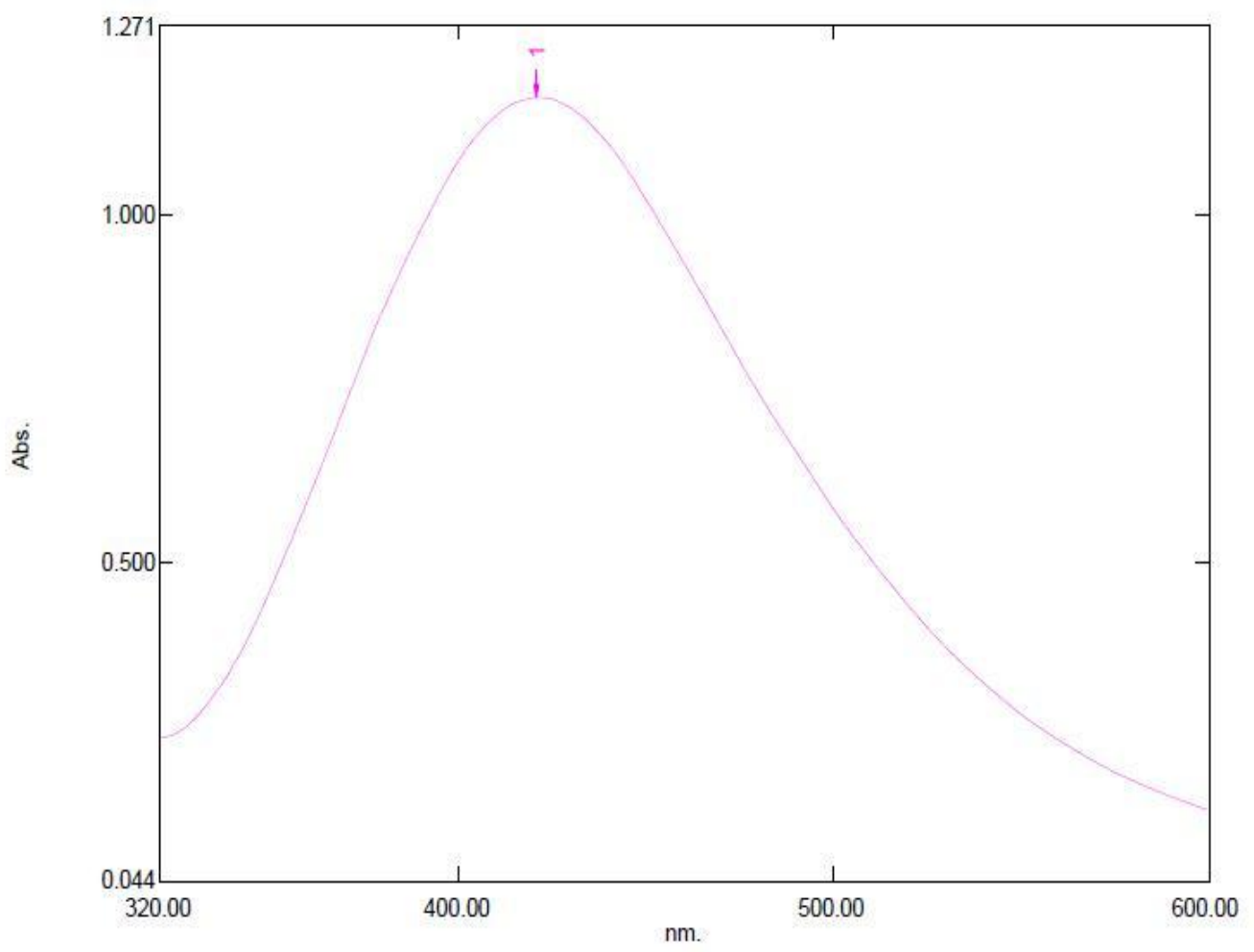

Fig.3 Morphology of biosynthesized Ag NPs analysed using scanning electron microscopy (SEM)

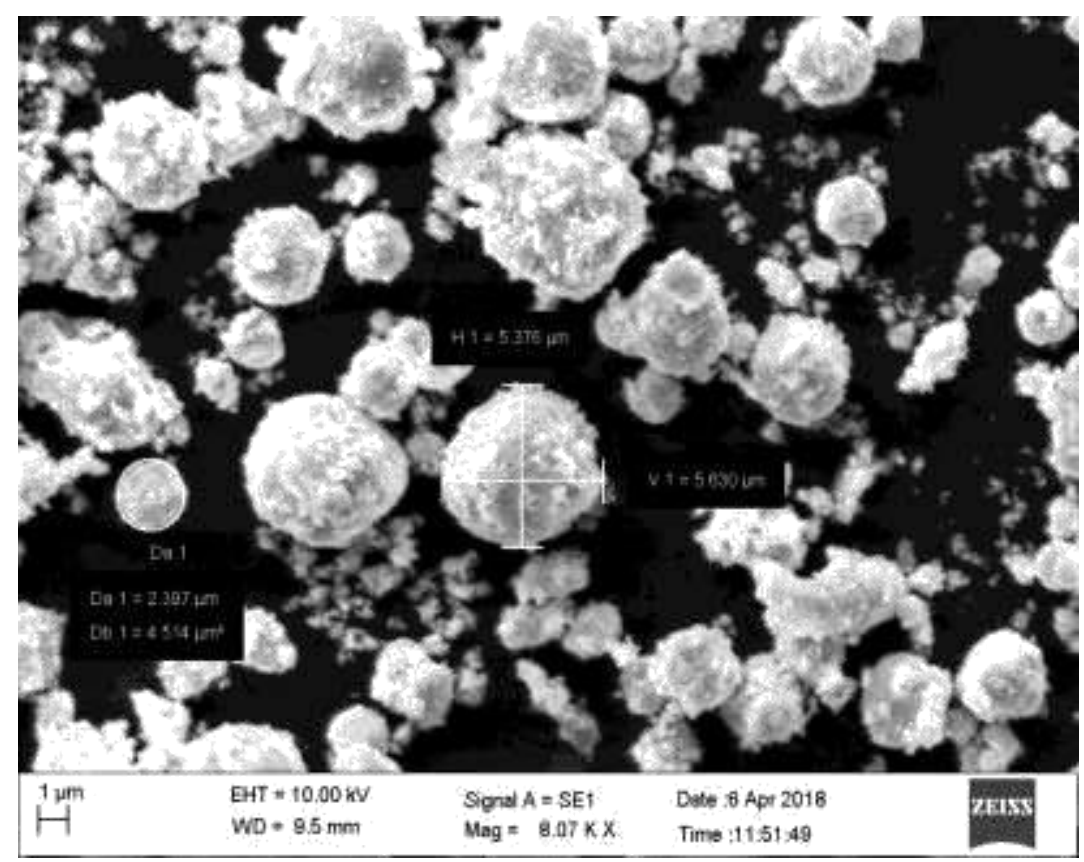


Fig.4 XRD pattern of biosynthesized Ag NPs using Achyranthes aspera root extract

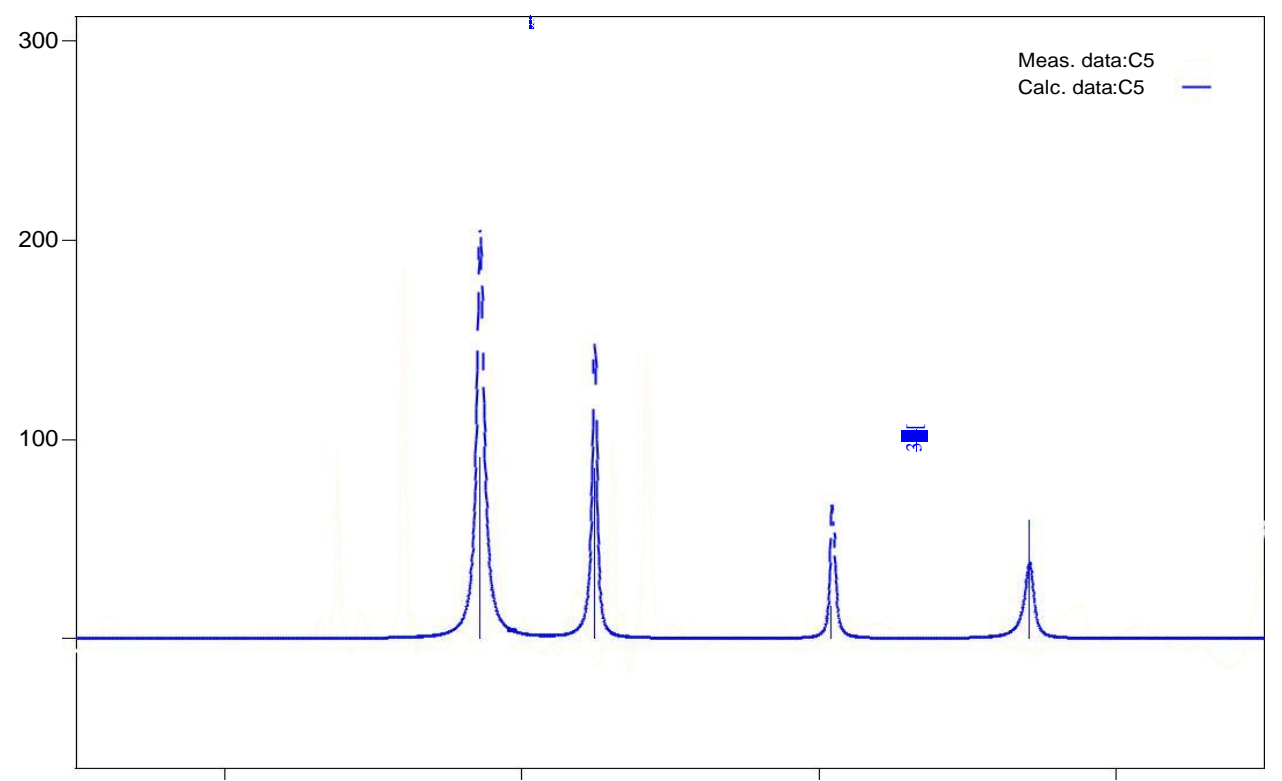

Fig.5 a) 2D and b) 3D images of standard Ag NPs using AFM

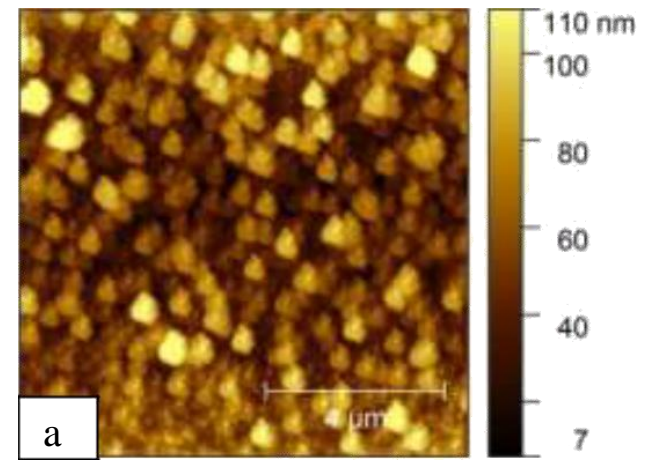

Some of the larger particles might be present because of aggregation due to the presence of cell components on the surface of nanoparticles and acted as capping agent (Vanaja et al., 2013). The present results are in good agreement with the findings of Kalidasan and Yogamoorthi (2014) who reported that, the biosynthesized Ag NPs were in spherical shape. Sivakumari et al., (2018), Allafchian et al., (2016) and Premasudha et al., (2015) for biosynthesized Ag NPs (spherical shape) using A. aspera, Phlomis leaf extract and Eclipta alba leaf extract as reducing agent, respectively.

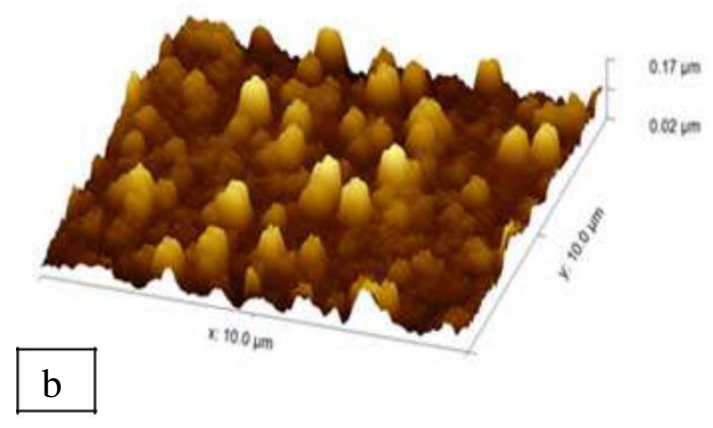

\section{Phase identification analysis}

XRD pattern showed four distinct diffraction peaks at $37.18^{\circ}, 44.90^{\circ}, 60.86^{\circ}$ and $74.16^{\circ}$ that were corresponding to (111) (200) (220) and (311) reflections planes of biosynthesized silver nanoparticles, respectively. The highest peak was observed at $37.18^{\circ}$ (111) reflection (Fig. 4). The XRD study confirmed that, the resultant nanoparticles were face centred cubic in nature and intensity of the peaks reflected high degree of crystallinity of silver nanoparticles. The peaks observed during XRD analysis were due to the presence of 
organic compounds in the extract and intensity of the peaks denoted the degree of crystallinity of the particles (Halawani, 2017). The unassigned peaks could be due to the crystallization of bio-organic phase on the surface of the nanoparticles (Ahmad and Sharma, 2012). Similar findings were also reported by Halawani (2017) who reported that, the silver nanoparticles biosynthesized using Zizyphus spinachristi L. aqueous leaf extract were face centred cubic in nature.

\section{Surface topology analysis}

Surface topology of biosynthesized silver nanoparticles was studied by atomic force microscope (AFM). AFM micrographs with a scanning area of $10 \times 10 \mu \mathrm{m}$ of silver nanoparticles in 2D and 3D images of the biosynthesized Ag NPs samples showed spherical particles with different sizes (Fig. 5). Height and width of the arbitrarily selected biosynthesized Ag NPs was 0.11 and 1.10 $\mu \mathrm{m}$, respectively. Other parameters such as roughness average of about $56.16 \mathrm{~nm}$ and root mean square roughness of about $66.85 \mathrm{~nm}$ were recorded for biosynthesized Ag NPs. Some nanoparticles were agglomerated in the sample which might be due to the deposition of the silver nanoparticles on the surface tending to form cluster together during AFM analysis. Also, the shape of the tip of AFM might cause misleading cross sectional views of the sample (Alahmad, 2013). Similar results were observed by Yadav et al., (2015) who reported that, the AFM analysis for biosynthesized Ag NPs using bacteria Pseudomonas sp. Hong et al., (2017) showed the AFM micrographs for silver thin films. The biosynthesis of silver nanoparticles using Achyranthes aspera root extract is an environmental friendly, simple and economically efficient route for synthesis of nanoparticles which could be an alternative to chemical and physical methods. The stable Ag NPs were found at optimum conditions of
$\mathrm{AgNO}_{3}$ of $1.50 \mathrm{mM}$, temperature at $45^{\circ} \mathrm{C}$ and $\mathrm{pH}$ of 9 for a period of 1 month.

\section{References}

Ahmad, N. and Sharma, S., 2012. Green synthesis of silver nanoparticles using extracts of ananas comosus. Green and Sustainable Chemistry. 2(4): 141-147.

Ahmed, S., Ahmad, M. and Ikram, S., 2014. Chitosan: A natural antimicrobial agentA review. Journal of Applicable Chemistry. 3(2): 493-503.

Alahmad., 2013. Preparation and characterization of silver nanoparticles. International Journal of Chem Tech Research. 6(1): 450-459.

Allafchian, A. R., Mirahmadi, S. Z., Jalali, S. A. H., Hashemi, S. S. and Vahabi, M. R., 2016. Green synthesis of silver nanoparticles using phlomis leaf extract and investigation of their antibacterial activity. Journal of Nanostructure in Chemistry. 6(4): 129-135.

Amaladhas, T. P., Usha, M. and Naveen, S., 2013. Sunlight induced rapid synthesis and kinetics of silver nanoparticles using leaf extract of Achyranthes aspera L. and their antimicrobial applications. Advanced Materials Letters. 4(10): 779785.

Balagurunathan, R., Radhakrishnan, M., Rajendran, R. B. and Velmurugan, D., 2011. Biosynthesis of gold nanoparticles by actinomycete. Indian Journal of Biochemistry and Biophysics. 48(2): 331-335.

Beg, M., Maji, A., Mandal, A. K., Das, S., Aktara, M. N., Pradeep, K., Jha. and Hossain, M., 2016. Green synthesis of silver nanoparticles using Pongamia pinnata seed: Characterization, antibacterial property and spectroscopic investigation of interaction with human serum albumin. Journal of Molecular Recognition. 30(1): 1-8. 
Bobbu, P., Netala, V. R., Aishwarya, S., Manohar, I. R., Reddy., Kotakadi, V. S. and Tartte, V., 2016. Rapid synthesis of silver nanoparticles using aqueous leaf extract of Achyranthes aspera and study of their antimicrobial and free radical scavenging activities. International Journal of Pharmacy and Pharmaceutical Science. 8(5): 341-346.

Das, D., Yang, Y., Brien, O. J. S., Breznan, D., Nimesh, S., Bernatchez, S., Hill, M., Sayari, A., Vincent, R. and Kumarathasan, P., 2014. Synthesis and physicochemical characterization of mesoporous $\mathrm{SiO}_{2}$ nanoparticles. Journal of Nanomaterials. 62(6): 11-12.

Djangang, C, N., Mlowe, S., Njopwouo, D. and Revaprasadu, N., 2015. One-step synthesis of silica nanoparticles by thermolysis of rice husk ash using nontoxic chemicals ethanol and polyethylene glycol. Journal of Applicable Chemistry. 4(4): 1218-1226.

Elumalai, E. K., Prasad, T. N. V., Hemachandran, J., Therasa, S. V., Thirumalai, T. and David, E. J., 2010. Antibacterial activity of bio stabilized silver nanoparticles. Indian Journal of Chemical Technology. 23(4): 520-526.

Habibi, B., Hadilou, H., Mollaer, S. and Yazdinezhad, A., 2017. Green synthesis of silver nanoparticles using the aqueous extract of Prangos ferulaceae leaves. International Journal of Nano Dimensions. 8(2): 132-141.

Hafez, R. A., Mosaad, A., Wahhab, A., Sehab, A. F., Al-Zahraa, A. and El-Din, K., 2017. Green synthesis of silver nanoparticles using Morus nigra leaf extract and evaluation their antifungal potency on phytopathogenic fungi. Journal of Applied Pharmaceutical Science. 7(2): 41-48.

Hahens, W. I., Oomen, A. G., Dejong, W. H. and Cassee, F. R., 2007. What do we (need to) know about the kinetic properties of nanoparticles in the body. Regulatory Toxicology and Pharmacology. 49(3): 217-229.

Halawani, E. M., 2017. Rapid biosynthesis method and characterization of silver nanoparticles using zizyphus spina christi leaf extract and their antibacterial efficacy in therapeutic application. Journal of Biomaterials and Nanobiotechnology. 8(1): 22-35.

Haq, I. U., Akhtar, K. and Malik, A., 2014. Effect of experimental variables on the extraction of silica from the rice husk ash. Journal of the Chemical Society of Pakistan. 36(3): 382-387.

Hong, R., Ji, J., Tao, C., Zhang, D. and Zhang, D., 2017. Fabrication of $\mathrm{Au} /$ graphene oxide/Ag sandwich structure thin film and its tunable energetics and tailorable optical properties. Material Sciences. 4(1): 223230.

Joseph, A. T., Prakash, P. and Narvi, S. S., 2016. Phytofabrication and characterization of copper nanoparticles using Allium sativum and its antibacterial activity. International Journal of Scientific Engineering and Technology. 4(2): 463-472.

Kalidasan M. and Yogamoorti A 2014. Biosynthesis of silver nanoparticles using Achyranthus aspera and its characterization. International Journal of Nanomaterials and Biostructures. 4(1): 5-11.

Kaviya, S., Santhanalakshmi, J., Viswanathan, B., Muthumary, J. and Srinivasan, K., 2011. Biosynthesis of silver nanoparticles using citrus sinensis peel extract and its antibacterial activity. Spectrochimica Acta Part A. 79(3): 594598.

Kupiec, A. S., Malina, D., Wzorek, Z. and Zimowska, M., 2011. Influence of silver nitrate concentration on the properties 
of silver nanoparticles. Micro and Nano Letters. 6(8): 656-660.

Mitra, P. and Meda., 2009. Optimization of microwave- vacuum drying parameters of aaskatoon berries using response surface methodology. Drying Technology. 27(1): 1089-1096.

Premasudha, P., Venkataramana, M., Abirami, M., Vanathi, P., Krishna, K. and Rajendran, R., 2015. Biological synthesis and characterization of silver nanoparticles using Eclipta alba leaf extract and evaluation of its cytotoxic and antimicrobial potential. Bulletin of Material Sciences, 38(4): 965-973.

Sivakumari, K., Ashok, K. and Rajesh, S., 2018, Achyranthes aspera mediated green synthesis of silver nanoparticles. Indo American Journal of Pharmaceutical Sciences. 5(1): 64-73.

Tran, Q. H., Nguyen, V. Q. and Tuan, A., 2013. Silver nanoparticles: synthesis, properties, toxicology, applications and perspectives. Advances in Natural Sciences: Nanoscience and Nanotechnology. 4(2): 1-18.

Triguna, N., Misra, R. S., Singh., Hari, S., Pandey, C., Prasad. and Singh, B. P., 1992. Antifungal essential oil and a long chain alcohol from Achyranthes aspera. Phytochemistry. 31(5): 18111812.

Umoren, S. A., Obot, I. B. and Gasem, Z. M., 2014. Green synthesis and characterization of silver nanoparticles using red apple (Malus domestica) fruit extract at room temperature. Journal of Material and Sciences. 5(3): 907-914.
Vanaja, M., Rajeshkumar, S., Paulkumar, K., Gnanajobitha, G., Malarkodi, C. and Annadurai, G., 2013. Kinetic study on green synthesis of silver nanoparticles using Coleus aromaticus leaf extract. Advances in Applied Science Research. 4(3): 50-55.

Vanaja, M., Rajeshkumar, S., Paulkumar, K., Gnanajobitha, G., Malarkodi, C. and Annadurai, G., 2013. Kinetic study on green synthesis of silver nanoparticles using Coleus aromaticus leaf extract. Advances in Applied Science Research. 4(3): 50-55.

Veerasamy, R., Xin, T. Z., Gunasagaran, S., Xiang, T. F. W., Yang, E. F. C., Jeyakumar, N. and Dhanaraj, S. A., 2011. Biosynthesis of silver nanoparticles using mangosteen leaf extract and evaluation of their antimicrobial activities. Journal of Saudi Chemical Society. 15(4): 113120.

Yadav, A., Theivasanthi, T., Paul, P. K. and Upadhyay, K. C., 2015. Extracellular biosynthesis of silver nanoparticles from plant growth promoting rhizobacteria pseudomonas sp. International Journal of Current Microbiology and Applied Sciences. 4(8): 1057-1068.

Zainala, N. A., Shukor, S. R. A., Wabb, H. A. A. and Razakb, K. A., 2013. Study on the effect of synthesis parameters of silica nanoparticles entrapped with rifampicin. Chemical Engineering. 32(7): 432-440.

\section{How to cite this article:}

Smitha, P.M., Sharanagouda Hiregoudar, Udaykumar Nidoni, K.T. Ramappa and Sushilendra. 2018. Stability of Biosynthesised Silver Nanoparticles Using Achyranthes aspera Roots and Its Characterization. Int.J.Curr.Microbiol.App.Sci. 7(09): 1566-1575. doi: https://doi.org/10.20546/ijcmas.2018.709.188 